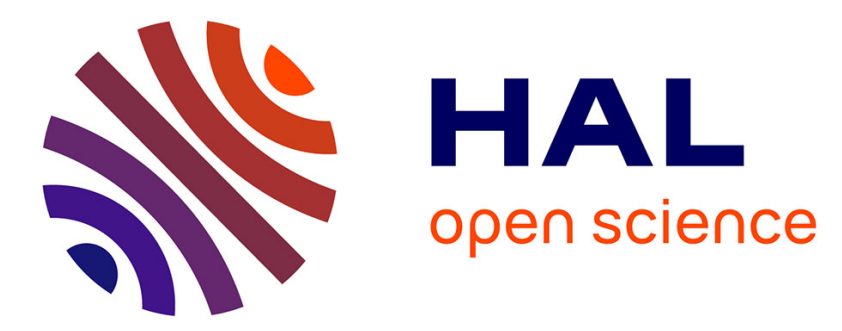

\title{
Heat Capacity and Neutron Diffraction of Low Doped Fe3-xZnxO4
}

\author{
A. Kozlowski, Z. Kakol, R. Zalecki, K. Knight, J. Honig
}

\section{To cite this version:}

A. Kozlowski, Z. Kakol, R. Zalecki, K. Knight, J. Honig. Heat Capacity and Neutron Diffraction of Low Doped Fe3-xZnxO4. Journal de Physique IV Proceedings, 1997, 07 (C1), pp.C1-591-C1-592. 10.1051/jp4:19971243 . jpa-00254929

\section{HAL Id: jpa-00254929 https://hal.science/jpa-00254929}

Submitted on 1 Jan 1997

HAL is a multi-disciplinary open access archive for the deposit and dissemination of scientific research documents, whether they are published or not. The documents may come from teaching and research institutions in France or abroad, or from public or private research centers.
L'archive ouverte pluridisciplinaire HAL, est destinée au dépôt et à la diffusion de documents scientifiques de niveau recherche, publiés ou non, émanant des établissements d'enseignement et de recherche français ou étrangers, des laboratoires publics ou privés. 


\title{
Heat Capacity and Neutron Diffraction of Low Doped $\mathrm{Fe}_{3-x} \mathrm{Zn}_{x} \mathrm{O}_{4}$
}

\author{
A. Kozlowski, Z. Kakol, R. Zalecki, K.S. Knight* and J.M. Honig** \\ Department of Solid State Physics, University of Mining and Metallurgy, al. Mickiewicza 30, 30-059 \\ Krakow, Poland \\ * ISIS, RAL, Chilton Didcot, Oxfordshire, OXI1 0QX, U.K. \\ ** Department of Chemistry, Purdue University, West Lafayette, IN 47907, U.S.A.
}

\begin{abstract}
We report on the heat capacity and neutron diffraction studies of $\mathrm{Fe}_{3-\mathrm{x}} \mathrm{Zn}_{\mathrm{x}} \mathrm{O}_{4}(\mathrm{x}<0.04)$ series. Adiabatic heat capacity measurements, performed on single crystals, confirm our earlier observations that in the range $x<0.012$ the Verwey transition is of first order, whereas for $0.012<x<0.035$ the transition character changes to second order. The change of transition order is accompanied by the clear difference in heat capacity baselines below Verwey transition temperature $T_{\mathrm{V}}$. The time-of-flight neutron diffraction data were collected at the High Resolution Powder Diffractometer in ISIS in the T range 4-240 K for two $\mathrm{Fe}_{3-\mathrm{x}} \mathrm{Zn}_{\mathrm{x}} \mathrm{O}_{4}$ samples with $\mathrm{x}$ falling within first and second order regime. The comparison of spectra for both samples shows that second order sample undergoes much smaller structure change than that observed for first order sample what was suggested by our heat capacity measurements results.
\end{abstract}

\section{INTRODUCTION}

In magnetite, near $T_{V}=120 \mathrm{~K}$, the electrical phase transition (Verwey transition) is observed which is accompanied by the crystal symmetry change and the anomaly in several physical properties [1-4]. Our resistivity and Seebeck coefficient measurements [5] performed on low doped $\mathrm{Fe}_{3-\mathrm{x}} \mathrm{Zn}_{\mathrm{x}} \mathrm{O}_{4}(\mathrm{x}<0.04)$ showed that in the range $0 \leq \mathrm{x} \leq 0.012$ the Verwey transition is of first order whereas in the range $0.012<x<0.04$ the transition changes to second order, similarly to nonstoichiometric magnetite $\mathrm{Fe}_{3(1-\delta)} \mathrm{O}_{4}[2]$. Despite the crystal symmetry change at $\mathrm{T}_{\mathrm{V}}$, lattice contribution to the Verwey transition itself and to the change of its character remains still unresolved. This is mainly because there are no systematic measurements of lattice parameters and low temperature crystal structure as a function of $\mathbf{x}$. To fill this gap we started heat capacity and neutron diffraction measurements for $\mathrm{Fe}_{3-\mathrm{x}} \mathrm{Zn}_{\mathrm{x}} \mathrm{O}_{4}$ series. The adiabatic heat capacity studies were performed on single crystalline samples in the temperature range $15-150 \mathrm{~K}$. Neutron data were collected on powdered single crystals at the High Resolution Powder Diffractometer in ISIS, Rutherford Appleton Lab., England. The t-o-f method was employed in $4.2-240 \mathrm{~K}$ temperature range. Single crystals were prepared by skull melter technique [6] and annealed under $\mathrm{CO} / \mathrm{CO}_{2}$ gas mixtures to establish appropriate stoichiometry [7]. $\mathrm{Fe}_{3-\mathrm{x}} \mathrm{Zn}_{\mathrm{x}} \mathrm{O}_{4}$ samples, used in measurements, were selected with $\mathrm{x}$ falling within first and second order regimes. Hereafter we refer to these compositions as "first order" and "second order" samples.

\section{RESULTS AND DISCUSSION}

Heat capacity data are presented in Fig. 1 as a plot of $C_{p} / T$ vs. T for samples with $x=0.011$ and $x=0.028$. The difference in the transition character is clearly visible in close correspondence with the results for $\mathrm{Fe}_{3(1-8)} \mathrm{O}_{4}$ [2]. Also heat capacity baselines for first and second order samples are significantly different below $T_{V}$, whereas above the transition they are nearly equal. Additionally, temperature dependence of Debye characteristic temperature $\theta_{D}$ shows $50 \mathrm{~K}$ jump at the $T_{V}$ for first order sample, while $\theta_{\mathcal{D}}$ goes smoothly through the transition for second order specimens. To understand this phenomenon we have analyzed several possible contributions to the heat capacity and we have found, in conclusion, that most likely it results from the difference in lattice dynamics for both type of specimens below the transition. This was supported by the literature report on the sharp increase of sound velocity in $\mathrm{Fe}_{3} \mathrm{O}_{4}$ when the sample is cooled down through the transition [8]. To check the conjecture about lattice difference we have performed neutron diffraction measurements. Full profile refinements were carried out using the Rietveld method. For both samples at temperatures above $T_{\mathrm{V}}$ the best fit was obtained assuming cubic Fd3m symmetry, in full agreement with the literature. Low temperature (below $\mathrm{T}=110 \mathrm{~K}$ ) diffraction pattern for first order sample showed clear splitting of $\langle\mathrm{hh} 0\rangle$ (with the intensity ratio $1: 1$ ) and $\langle\mathrm{hhh}>$ (intensity ratio $3: 1$ ) cubic reflection which rapidly coalesce into one at the transition. This is again in agreement with literature reports about rhombohedral elongation of the original cubic cell along $<111>$ direction which is one of the indications of the low temperature monoclinic symmetry [9]. The low temperature splitting of the relevant $\langle\mathrm{hhh}\rangle$ and $\langle\mathrm{hh} 0\rangle$ reflections for second 
order sample is much smaller. From the refinement procedure we obtained cubic lattice parameters a for high temperature structure, rhombohedral lattice constants $a_{r}$ for low temperature phase and the distortion angle $\gamma_{r}$. These lattice parameters are compared on Fig. 2. Clearly, there is a discontinuity in temperature dependence of lattice constant for first order sample in contrast to the second order specimen. Also, monoclinic angle $\beta_{\mathrm{M}}$, calculated from $\gamma_{\mathrm{r}}\left(\cos \beta_{\mathrm{M}}=-\sqrt{2} \cos \gamma_{\mathrm{r}}\left(1+\cos \gamma_{\mathrm{r}}\right)^{-1 / 2}\right)$ is significantly different for both type of specimens: at $\mathrm{T}=4.2 \mathrm{~K}, \beta_{\mathrm{M}}=0.237^{\circ}$ for $\mathrm{x}=0.0072$ and $\beta_{\mathrm{M}}=0.125^{\circ}$ for $\mathrm{x}=0.0249$. For the comparison $\beta_{\mathrm{M}}$ is equal to $0.239^{\circ}$ and rhombohedral lattice constant $\mathrm{a}_{\mathrm{r}}=8.3895 \AA$ for $\mathrm{Fe}_{3} \mathrm{O}_{4}$ measured at $4.2 \mathrm{~K}$.

All the above presented data indicate that lattice for first order samples changes much more significantly at the transition than for second order specimens.

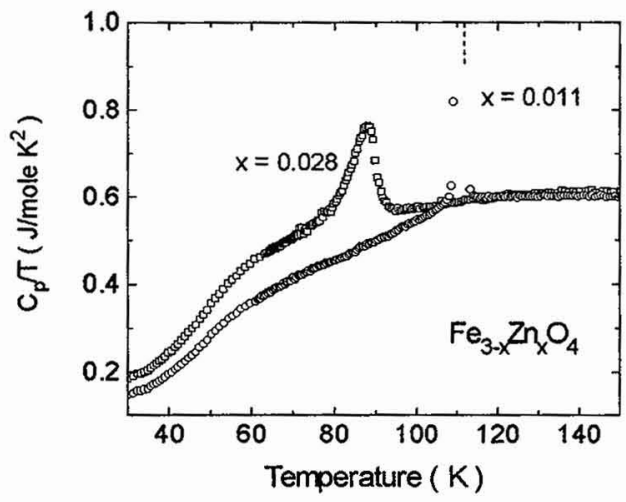

Figure 1:Temperature dependence of heat capacity for first and second order $\mathrm{Fe}_{3-\mathrm{x}} \mathrm{Zn}_{\mathrm{x}} \mathrm{O}_{4}$ samples.

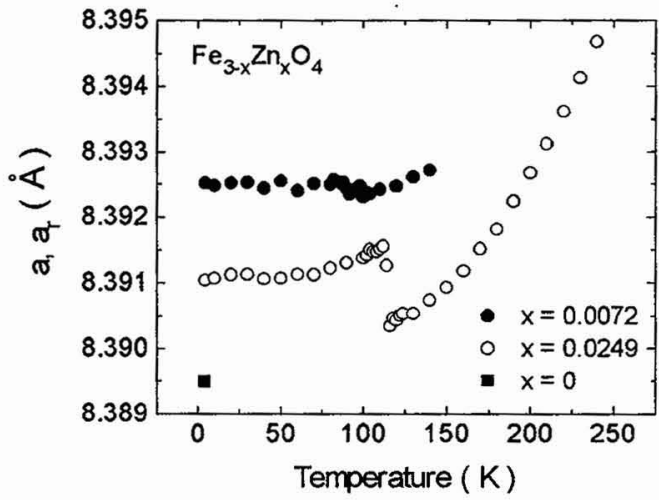

Figure 2: Temperature dependence of cubic a and thombohedral $a_{i}$ lattice parameters for first and second order $\mathrm{Fe}_{3-\mathrm{x}} \mathrm{Zn}_{\mathrm{x}} \mathrm{O}_{4}$ samples.

\section{CONCLUSIONS}

In conclusion we have presented heat capacity data for $\mathrm{Fe}_{3-\mathrm{x}} \mathrm{Zn}_{\mathrm{x}} \mathrm{O}_{4}$ showing first and second order Verwey transition. The difference in heat capacity baselines was observed below transition temperature in these two regimes while above $T_{V}$ the data merge. This difference was analyzed and correlated with the distinct lattice properties between these classes of materials. We tried to verify this suggestion through the powder neutron diffraction scattering studies. We have found that the low temperature rhombohedral distortion is much smaller for second order samples than for the first order specimen.

This suggests that lattice contribution should be considered in the analysis of possible interactions leading to the Verwey transition and to the change of its character with doping and nonstoichiometry.

\section{Acknowledgments}

Some of us (A.K, Z.K., and R.Z.) gratefully acknowledge support from the British Council, Rutherford Appleton Laboratory, and Faculty of Physics and Nuclear Techniques of University of Mining and Metallurgy.

\section{References}

1. Z.Kakkol, Solid State Chem., 88, (1990) 104.

2. P. Shepherd, J. W. Koenitzer, R. Aragón, J. Spałek, J. M. Honig, Phys. Rev. B43, (1991) 8461.

3. Shirane, S. Chikazumi, J. Akimitsu, K. Chiba, M. Matsui, and Y. Fujii, J. Phys. Soc. Japan 39, (1975) 947.

4. M. Zuo, J. C. H. Spence, and W. Petuskey, Phys. Rev. B42, (1990) 8451.

5. P.Wang, Z.Kakkol, M.Wittenauer, and J.M.Honig, Phys. Rev. B42 , (1990) 4553.

6. Harrison, R. Aragón, Mater. Res. Bull. 13, 1097 (1978),

7. P. Shepherd and C. J. Sandberg, Rev. Sci. Instrum. 55, (1984) 1696.

8. Siratori, Y. Kino, J. Magn. Magn. Mat. 20, (1980) 87.

9. Iizumi, T. F. Koetzle, G. Shirane, S. Chikazumi, N. Matsui, and S. Todo, Acta Cryst. B38, (1982) 2121. 